\title{
APPLYING COBB-DOUGLAS STOCHASTIC FRONTIER PROFIT FUNCTION: A CASE STUDY OF HOALOC- MANGO IN THE MEKONG DELTA, VIETNAM
}

\author{
TRUONG HONG VO TUAN KIET ${ }^{1,2,3}$, NGUYEN THI KIM THOA ${ }^{1} \&$ PHAM THI NGUYEN ${ }^{1}$ \\ ${ }^{1}$ Mekong Delta Development Research Institute, Can Tho University, Vietnam \\ ${ }^{2}$ SEARCA Scholar, Philippines \\ ${ }^{3}$ Institute of Agricultural and Food Policy Studies, Putra University, Malaysia
}

\begin{abstract}
This study employed a Cobb-Douglas stochastic frontier profit function to measure the level of economic efficiency and its determinants. A structured questionnaire was used to collect data from 382 sample observations $(118,130$, and 134 observations for seasons 1, 2, and 3, respectively). The research estimated a mean economic efficiency of $28.65 \%, 19.65 \%$, and $28.00 \%$ in seasons 1,2 , and 3 , respectively. The study found out the credit access variable to be positively and significantly influencing on economic efficiency in all three seasons. Besides, the results of the analysis indicated that the root fertiliser price and the land area were important factors in season 1 at the $1 \%$ significance level. In season 2, the price of fungicide, root fertiliser, leaf fertiliser influenced substantially on mango farmers' profit at the conventional significance levels. In season 3, the leaf fertiliser price, labour price and land area played a major role in economic efficiency.
\end{abstract}

Keywords: HoaLoc-mango, profit efficiency, the Mekong Delta.

\section{INTRODUCTION}

Mango is one of the most prevalent tropical fruit in developing countries over the world, especially is in Asia, in which Vietnam is mango volume about 836,000 tons in 2017 [1]. Mango is a specialty fruit of the tropical region, including Vietnam. Mango is not only a favourite food, but it also ranks the top of nutritious fruits. Mango is the most sought after seasonal tropical fruit but production in Vietnam remains small. With improved technologies in production and post-harvest operations, including the new techniques of producing offseason fruits, there is a great prospect for large-scale cultivation of mango in Vietnam.

HoaLoc-mango is one of the most well-known varieties of mango under cultivation in the Mekong Delta (MD), for its aroma and sweetness. It has presently grown in many provinces of the Mekong river delta like Tien Giang, Hau Giang, Vinh Long, Dong Thap, and so on. Mango transplantation and seedling selection with an application of modern techniques are done with an aim to raise the quality and productivity. The MD has provided to international and domestic market about fresh mango 460,000 ton/year with area nearly 40,000 ha [2].

Mango cultivation in The MD was primarily small farmers activity. Small farmers faced numerous challenges in utilization of available resources which affected their efficiency, productivity, awareness of quality requirements, poor technical skills and difficulties in funding investment [3]. According to Mbanasor and Kalu [4] and Mwita [5], age has a positive influence on economic efficiency among farmers; however, the variable has a negative effect on EE because older is unable to combine the available technology in certain studies [6]-[10]. Moreover, Khan and Ali [12] and Ogunniyi [14] contended that farming experience had a positive influence on profit efficiency as farming experience increases, profit efficiency of farmers rise. A statistical significant correlation between education and profit efficiency is found in some studies [5], [11]-[14], implying more years of schooling would lead to higher EE. Mbanasor and Kalu [4] and Khan and Ali [12] pointed out that credit access are 
more economically efficient than farmer who does not have, while Mwita [5] claimed that receiving credit contributed to farmers' economic inefficiency. In addition, Abdur [6] and Daniel [8] suggested that farm land size had a negative effect on EE of the potato farms and it was significant at $1 \%$ level. Therefore, the objective of this study was to alleviate different constraints in HoaLoc-mango production of various seasons of the year in the MD. The study specifically found out effective disparities among mango seasons, the relationships between inputs price and output in HoaLoc-mango production, determinants of economic efficiency in HoaLoc-mango farmers.

\section{MATERIALS AND METHODS}

\subsection{Sampling techniques}

The Mekong Delta (MD) region was purposively selected because of its comparative advantage in mango production in Vietnam, as it accounts for $55 \%$ of the mango production volume and for $50 \%$ of the mango production area in Vietnam. Then, Dong Thap, Tien Giang, Vinh Long, and Hau Giang provinces were selected because, combined, they account for approximately $61 \%$ of the mango production volume and $52 \%$ of the mango production area in MD [2]. Also, a simple random sampling technique was used to select 382 sample observations (118, 130, and 134 observations for seasons 1, 2, and 3, respectively).

\subsection{Conceptual underpinning}

According to Fried et al. [15], productivity is the output to input ratio. Productivity is a residual that reflects the production differences among producers over the same time period, or variations in a given time period (productivity growth). It could be defined as the unexplained part of the output variation of output after having taken the input variation in inputs into account.

Meanwhile, Daraio and Simar [16] and Lovell [17] contended that efficiency is also a residual, however it also requires a benchmark (a best practice) in order to develop. The authors referred to the comparison of the observed and optimal values of outputs and inputs. Moreover, Koopmans [18] suggested that an input output vector is technically efficient if, and only if, increasing any output or decreasing any input is possible only by decreasing some other output or increasing some other input.

Efficiency is usually perceived as EE and has one technical and one allocative component. The technical component refers to the ability to avoid waste, either by producing as much output as input usage allows (output orientation) or by using as little input as required by technology and the production output (input orientation). The allocative component refers to the ability to combine inputs and/or outputs in optimal proportions in light of prevailing prices.

Therefore, if technical efficiency only pertains to adhering to one's own production plan and does not require any assumptions regarding on the producer's behaviour, EE needs an a priori on the economic objective of the producer and information on relevant prices.

In order to achieve the objectives of this study, the stochastic frontier production and profit function models were used to analyse the socio-economic characteristics and EE, respectively, of the farmers.

The stochastic profit function was defined as:

$$
\pi *=\frac{\pi}{\rho}=h(q i, z) \exp (v i-u i)
$$


where $\pi *=$ normalised profit of the $i$ th farmer; $\frac{\pi}{\rho}=$ description of the normalised profit; $q i=$ vector of variable inputs; $Z=$ vector of fixed input(s); $P=$ output price used to normalise the model variables; $\pi=$ farmer's profit defined as the total revenue minus the total production cost (this context, the mango revenue consisted of returns from the sales of mango production, while the total cost consisted of the cost of fertiliser, labour, and agrochemical costs $) ; \exp (v i-u i)=$ composite error term.

The profit/EE of an individual farmer in the context of the stochastic frontier profit function was derived as a ratio of the predicted, observed, or actual profit $(\pi i)$ to the corresponding predicted maximum profit $(\pi i *)$ for the best farm or frontier profit given the price of variable inputs and the level of fixed factor(s) of production of that farmer. Mathematically, it was expressed as follows:

$$
\mathrm{EE}=\frac{\pi i}{\pi i *}=\frac{(q i, z) \exp (v i-u i)}{(q i, z) \exp (v i)},
$$

then,

$$
\mathrm{EE}=\frac{\exp (v i-u i)}{\exp (v i)}
$$

The stochastic disturbance term (ei) consisted of two independent elements: " $v$ " and " $u$ ". The symmetric two-sided error term ( $v)$ accounted for random variation in profit attributed to factors outside the farmer's control (random effects, measurement errors, omitted explanatory variables and statistical noise). The one-sided component (u) was a nonnegative error term accounting for the inefficiency of the farm. Thus, it represented the profit shortfall from its maximum possible value that would be given by the stochastic profit frontier. However, when $u=0$, it implied that the farm profit lied on the efficiency frontier (i.e. $100 \%$ profit efficiency) and $u<0$ implied that the farm profit lied below the efficiency frontier. Both $v$ and $u$ were assumed to be independently and normally distributed with zero means and constant variance [19].

\subsection{Empirical model}

A multiple regression model based on the stochastic frontier profit function which assumed the Cobb-Douglas functional form, was employed to determine the profit efficiency of paddy producers in the study area. The frontier model, estimated according to Sunday et al. [19], was therefore specified as follows:

$$
\ln \pi_{i}^{*}=\beta \mathrm{o}+\beta 1 \ln X^{*} 1+\beta 2 \ln X^{* 2}+\beta 3 \ln X^{*} 3+\beta 4 \ln X^{*} 4+\beta 5 \ln X^{*} 5+\beta_{k} \ln X_{k}^{*}+V i-U i .
$$

The translog production function is alternatively defined as follows:

$$
\begin{aligned}
& \ln \pi_{i}^{*}=\beta o+\beta 1 \ln X^{*} 1+\beta 2 \ln X^{*} 2+\beta 3 \ln X^{*} 3+\beta 4 \ln X^{*} 4+\beta 5 \ln X^{*} 5+\beta_{6} \ln \left(X_{k}^{*}\right)+ \\
& 0.5 \beta 7\left(\ln X^{*} 1\right)^{2}+0.5 \beta 8 \ln \left(\ln X^{*} 2\right)^{2}+0.5 \beta 9 \ln \left(\ln X^{*} 3\right)^{2}+0.5 \beta 10 \ln \left(\ln X^{*} 4\right)^{2}+ \\
& 0.5 \beta 11 \ln \left(\ln X^{*} 5\right)^{2}+0.5 \beta_{12}\left(X_{k}^{*}\right) 2+\beta 13 \ln X^{*} 1 \ln X^{*} 2+\beta 14 \ln X^{*} \ln X^{*} 3+ \\
& \beta 15 \ln X^{*} 1 \ln X^{*} 4+\beta 16 \ln X^{*} 1 \ln X^{*} 5+\beta 17 \ln X^{*} 1 \ln X^{*}{ }_{k} \beta 18 \ln X^{*} 2 \ln X^{*} 3+\beta 19 \ln X^{*} 2 \ln X^{*} 4 \\
& +\beta 20 \ln X^{*} 2 \ln X^{*} 5+\beta 21 \ln X^{*} 2 \ln X^{*}{ }_{k}+\beta 22 \ln X^{*} 3 \ln X^{*} 4+\beta 23 \ln X^{*} 3 \ln X^{*} 5+ \\
& \beta 24 \ln X^{*} 3 \ln X^{*}{ }_{k}+\beta 25 \ln X^{*} 4 \ln X^{*} 5+\beta 26 \ln X^{*} 4 \ln X^{*} k+\beta 27 \ln X^{*} 5 \ln X^{*}{ }_{k}+V i-U i,
\end{aligned}
$$

where:

$\mathrm{Ln}=$ Natural logarithm,

$\pi_{i}^{*}=$ Normalised profit computed for $i$ th farmer,

$X_{1}^{*}=$ Price of pesticide (VND/litres) normalised by price of mango, 
$X_{2}^{*}=$ Price of fungicide (VND/litres) normalised by price of mango,

$X_{3}^{*}=$ Price of root fertiliser (VND/kg) normalised by price of mango,

$X_{4}^{*}=$ Price of leaf fertiliser (VND/kg), (sprayed on mango leaves to induce flowering in mango trees) normalized by price of mango,

$X_{5}^{*}=$ Price of labour (VND/man day) normalised by price of mango,

$X_{k}=$ Area of land cultivated (cong $=1,000 \mathrm{~m}^{2}$ ),

$\beta_{0}, \beta_{1 \ldots 5}$, and $\beta_{k}$ are parameters to be estimated, represents statistical disturbance term and

$u_{i}=$ represents profit inefficiency effects of $i$-th farmer.

The determinants of the profit inefficiency of the mango farmers were modelled following specific farmer characteristics in the study area, according to Ogunniyi [14]. The profit inefficiency was determined from the following equation:

$$
u_{i}=\alpha_{0}+\sum_{r=1}^{9} \alpha_{r} Z_{r}+\mathbf{k}
$$

where:

$\boldsymbol{u}_{\boldsymbol{i}}=$ Profit inefficiency of i-th farmer,

$\alpha_{0}$ and $\alpha_{r}=$ Parameters to be estimated,

$Z_{r}=$ Variables explaining inefficiency effects, $\mathrm{r}=1,2,3 \ldots ., \mathrm{n}, \mathrm{k}$ is truncated random variable,

$\mathrm{Z}_{1}=$ Farmer's age (year),

$Z_{2}=$ Level of education (years spent in acquiring formal education),

$\mathrm{Z}_{3}=$ Farming experience (year),

$\mathrm{Z}_{4}=$ Credit access (access $=1$, no access $=0$ ),

Z5 = Payment for agro-input wholesaler (ending of crop $=1$, payment immediately $=0$ ),

$\mathrm{Z}_{6}=$ Wrapping bag (wrap $=1$, no wrap $=0$ ) (applied mango wrap technique against incursion of pest, insect),

$\mathrm{Z}_{7}=$ Market access (access $=1$, no access $=0$ ),

$\mathrm{Z}_{8}=$ Classifying sale (classification $=1$, no classification $=0$ ) (selling mango is classified including: first level with best price, second level with medium price, and third level with lowest price),

$\mathrm{Z}_{9}=$ Plant density (plants/ha).

The estimates for all the parameters of profit functions and inefficiency model were obtained by maximizing the likelihood function on the FRONTIER 4.1 program.

\section{RESULTS AND DISCUSSION}

\subsection{Estimation procedure}

Harvesting seasons in Mekong Delta have taken place round year with four main periods including: April-June (Natural season), February-April (Early season), August-October (Off-season), November-February (Late/festival season). Selecting of farming season has been determined by mango farmers. It usually is two seasons/year or maximum three seasons/year because the period from flowering to harvest of mango spend four months/season.

To select the lead functional form for the data, we tested a hypothesis based on the generalised likelihood ratio (LR) test $=-2\{\log [\mathrm{L}(\mathrm{H} 0)-\log [\mathrm{L}(\mathrm{H} 1)]\}$ equation was used for the LR test. The first null hypothesis was that the Cobb-Douglas profit function was the best fit for the data. According to our results, the null hypothesis was rejected in all three cases, because the lambda values $(\boldsymbol{\lambda} \mathbf{1}=12.62, \lambda \mathbf{2}=10.70, \lambda \mathbf{3}=6.44)$ were less than critical value (32.67) at the 5\% significance level, thereby suggesting that the Cobb-Douglas form was the best functional form for the data (Table 1). 
Table 1: Generalised likelihood ratio test for stochastic profit model.

\begin{tabular}{|l|c|c|c|c|c|c|c|}
\hline Season & $\begin{array}{c}\text { Null } \\
\text { hypotheses }\end{array}$ & $\begin{array}{c}\text { Log } \\
\text { likelihood } \\
\left(\mathrm{H}_{0}\right)\end{array}$ & $\begin{array}{c}\text { Log } \\
\text { likelihood } \\
\left(\mathrm{H}_{1}\right)\end{array}$ & $\begin{array}{c}\text { Test } \\
\text { statistic } \\
(\lambda)\end{array}$ & $\begin{array}{c}\text { Degree of } \\
\text { freedom }\end{array}$ & $\begin{array}{c}\text { Critical } \\
\text { value } \\
(5 \%)\end{array}$ & Decision \\
\hline Season 1 & $\begin{array}{c}\text { Cobb-Douglas } \\
\text { was the best fit }\end{array}$ & -256.09 & -249.78 & 12.62 & 21 & 32.67 & $\begin{array}{c}\text { Not } \\
\text { rejected }\end{array}$ \\
\hline Season 2 & $\begin{array}{c}\text { Cobb-Douglas } \\
\text { was the best fit }\end{array}$ & -287.34 & -281.99 & 10.70 & 21 & 32.67 & $\begin{array}{c}\text { Not } \\
\text { rejected }\end{array}$ \\
\hline Season 3 & $\begin{array}{c}\text { Cobb-Douglas } \\
\text { was the best fit }\end{array}$ & -289.80 & -286.58 & 6.44 & 21 & 32.67 & $\begin{array}{c}\text { Not } \\
\text { rejected }\end{array}$ \\
\hline
\end{tabular}

* Critical values with asterisk were taken from Kodde and Palm (1986). For these variables the $\lambda$ statistic was distributed following a mixed $\chi^{2}$ distribution.

The expected parameters and the associated statistical test results obtained from the MLE analysis) of the translog and the Cobb-Douglas production function based on the stochastic frontier profit function for key mango farmers in the MD are presented in Table 2. The sigma squares $\left(\sigma^{2}\right)$ were $201.48,29.78$, and 313.66 in seasons 1,2 , and 3 , respectively. All sigma squares were significantly different from zero, which suggested a good fit of the models and correctness of the specified distributional assumptions. In addition, the gamma parameters $\left(\gamma_{1}=0.9995, \gamma_{2}=0.9999\right.$, and $\left.\gamma_{3}=0.9997\right)$ were quite high and significant at the $1 \%$ level of probability, thereby implying that $99.9 \%$ of the variation in three seasons resulted from the profit efficiency of the sampled farmers rather than from random variability.

Table 2: MLE estimates for SFA model of HoaLoc-mango in the Mekong Delta.

\begin{tabular}{|l|c|c|c|c|c|c|}
\hline \multirow{2}{*}{ Variables } & \multicolumn{2}{|c|}{ Season 1 } & \multicolumn{2}{c|}{ Season 2 } & \multicolumn{2}{c|}{ Season 3 } \\
\cline { 2 - 7 } & Coef & SE & Coef & SE & Coef & SE \\
\hline HoaLoc-mango [Dependent variable: Ln profit (vnd)] \\
\hline Constant & $3.833^{* * *}$ & 1.550 & $7.741^{* * *}$ & 0.455 & $8.679^{* * *}$ & 0.578 \\
\hline$\left(\mathrm{X}_{1}\right)$ Ln pesticide price (vnd/litres) & -0.019 & 0.182 & -0.116 & 0.174 & -0.139 & 0.166 \\
\hline$\left(\mathrm{X}_{2}\right)$ Ln fungicide price (vnd/litres) & 0.290 & 0.314 & $0.559^{* * *}$ & 0.111 & 0.118 & 0.214 \\
\hline$\left(\mathrm{X}_{3}\right)$ Ln root fertiliser price $(\mathrm{vnd} / \mathrm{kg})$ & $-1.524^{* * *}$ & 0.539 & $-0.390^{* *}$ & 0.168 & 0.013 & 0.149 \\
\hline$\left(\mathrm{X}_{4}\right)$ Ln leaf fertiliser price $(\mathrm{vnd} / \mathrm{kg})$ & 0.553 & 0.384 & $-0.576^{*}$ & 0.282 & $0.304^{*}$ & 0.199 \\
\hline$\left(\mathrm{X}_{5}\right)$ Ln labour price $(\mathrm{vnd} / \mathrm{day})$ & 0.330 & 0.708 & 0.134 & 0.434 & $-0.554^{* *}$ & 0.322 \\
\hline$\left(\mathrm{X}_{6}\right)$ Ln land area (cong $\left.=1,000 \mathrm{~m}^{2}\right)$ & $0.713^{* * *}$ & 0.159 & $0.191^{*}$ & 0.120 & $0.454^{* * *}$ & 0.123 \\
\hline Diagnostic statistics & & & & & & \\
\hline Sigma square $\left(\sigma^{2}\right)$ & 201.48 & & 29.78 & & 313.66 & \\
\hline Gamma $(\gamma)$ & $0.9995^{* * *}$ & & $0.9999^{* * *}$ & & $0.9997^{* * *}$ & \\
\hline Log-likelihood function & -256.09 & & -287.33 & & -289.80 & \\
\hline Observations $(\mathrm{N})$ & 118 & & 130 & & 134 & \\
\hline
\end{tabular}

Source: Field Survey Data, 2018.

* Significant at $10 \%$ level, ${ }^{* *}$ significant at $5 \%$ level, $* * *$ significant at $1 \%$ level.

For season 1, the results of the analysis of the estimated model demonstrated that the coefficients of the land area were positive and statistically significant at $1 \%$ level. The positive relationship of the land area suggested that a $10 \%$ increase in the land area would lead to a $7.13 \%$ profit rise. This meant that there was scope for increasing profit by expanding land area. It indicated the fact that HoaLoc-mango farmers were operating at a small-scale level; therefore, increasing their cultivated land area will improve profit, other things being equal. However, the root fertiliser price variable had a negative effect on profit of 
HoaLoc-mango growers at the $1 \%$ significance level, thereby implying that a $10 \%$ growth in root fertiliser price would result in a $15.24 \%$ decrease in profit obtained from HoaLoc-mango production. This showed that the variable played an important role in profit efficiency of HoaLoc-mango producers. Regarding season 2, the results show that the coefficients of the explanatory variables of the fungicide price and land area in the stochastic profit function were a positive effect at the $1 \%$ and 5\% significance level, respectively. Alternatively, a $10 \%$ increase in the fungicide and land area would result in approximately a $5.59 \%$ and $1.91 \%$ increase, respectively, in the profit incurred by mango production. On the other hand, a $10 \%$ increase in the root fertiliser and leaf fertiliser would lead to a $3.90 \%$ and $5.76 \%$, respectively, profit decline of HoaLoc-mango growers at the conventional significance levels.

Turning to season 3 , the labour price variable was negative influence with coefficient of 0.554 at the $5 \%$ significance level. It meant that available labour was unable to efficiently manage along with other inputs to result in redundancy and diminishing return to labour. Furthermore, the positively signed and significant coefficient of the leaf fertiliser price $(0.304)$, and the land area $(0.454)$ at the $10 \%$, and $1 \%$ significance level, respectively, thereby implying that a $10 \%$ increase in the leaf fertiliser price and cultivated land area would lead to $9.706 \%$ profit increase in HoaLoc-mango farmers. By contrast, the profit of the HoaLoc-mango farmer was a negative relationship $(-0.9067)$ with the root fertiliser price at the $1 \%$ level, thereby suggesting that the more higher the price, the lower the profit of the HoaLoc-mango growers.

\subsection{Profit inefficiency function}

The variables influencing inefficiency were specified as those that are relating to farmers' socio-economic characteristics. The analysis of the inefficiency model showed that the signs and significance of the estimated coefficients have important implications on profit efficiency of HoaLoc-mango producers (Table 3).

Table 3: MLE of the determinants of economic inefficiency score.

\begin{tabular}{|l|c|c|c|c|c|c|}
\hline \multirow{2}{*}{ Variable } & \multicolumn{2}{|c|}{ Season 1 } & \multicolumn{2}{c|}{ Season 2 } & \multicolumn{2}{c|}{ Season 3 } \\
\cline { 2 - 7 } & Coef & SE & Coef & SE & Coef & SE \\
\hline Constant & -137.881 & 121.787 & 0.522 & 1.011 & -151.533 & 195.028 \\
\hline Age (Z1) & 1.133 & 1.000 & $-0.136^{* * *}$ & 0.054 & 1.214 & 1.491 \\
\hline Education (Z2) & 0.869 & 0.843 & $0.401^{* *}$ & 0.188 & 0.980 & 1.353 \\
\hline Farming experience (Z3) & 0.057 & 0.121 & 0.095 & 0.096 & -0.586 & 0.645 \\
\hline Credit access (Z4) & $-18.244^{* *}$ & 8.159 & $-1.861^{* *}$ & 1.081 & $-13.667^{*}$ & 9.999 \\
\hline Payment for agro-input (Z5) & 26.964 & 19.154 & $2.153^{* *}$ & 1.189 & 34.592 & 44.591 \\
\hline Wrapping bag (Z6) & 6.290 & 4.205 & $-2.257^{* *}$ & 1.222 & -34.593 & 20.844 \\
\hline Market access (Z7) & -8.955 & 11.126 & $-5.463^{* * *}$ & 1.462 & -21.536 & 23.230 \\
\hline Classifying sale (Z8) & 18.388 & 17.101 & $7.081^{* * *}$ & 1.806 & 16.064 & 17.803 \\
\hline Plant density (Z9) & $-0.049^{*}$ & 0.032 & -0.001 & 0.006 & -0.039 & 0.045 \\
\hline
\end{tabular}

Source: Field Survey Data, 2018.

* Significant at the $10 \%$ level, ** significant at the $5 \%$ level, $* * *$ significant at the $1 \%$ level.

Note: A negative sign in the parameters of the inefficiency function means that the associated variable had a positive effect on economic efficiency, and vice versa. 
The parameters' estimates pointed out that the coefficient of the age, wrapping bag, and market access were found to have a positive and a significant impact on farmers' profit efficiency at the conventional significance levels in season 2. More specifically, the coefficient of the market access was positive and significant at the $1 \%$ probability level, thereby showing that the variable had a positive influence on economic efficiency among the mango producers sampled.

Moreover, the wrapping bag variable were positive and significant effect on economic efficiency. The positive sign of the wrapping bag variable indicated that if farmers use bags to wrap mangoes in production, their profit could increase. The main reason for this is that farmers focused on quality rather than quantity and they only wrapped high quality mango fruits, while also securing low wrapping bag costs, thereby achieving high selling prices. Besides, the age variable was identified positive effect on profit of HoaLoc-mango farmers. The similar finding was obtained by Mbanasor and Kalu [4] and Mwita [5]. However, the result was against with some previous studies [6]-[10], [12], [20] who stated that farmers were older, they were difficult to apply the available technology and had a negative effect on profit efficiency.

Also, in season 2, variables of education, classifying sale, and payment for agro-input on the ending of the harvest season were negative and statistical meaning at the conventional significance levels. In detail, the education variable had negative coefficients and was highly significant at the 5\% level. The educational level showed a negative impact on the profit of HoaLoc-mango farmers, meaning a lack of education might not be considered as an element causing economic inefficiency. This result concurred with those of Mbanasor and Kalu [4] and Okoye and Onyenwaku [21]. However, the research differed with some studies [5], [8], [11], [13] who found a statistically significant correlation between education and economic efficiency.

Particularly, the coefficient of the credit access was positive and significant influence on economic efficiency in all three seasons at the conventional significance levels, thereby implying that farmers who had credit access was more economically efficient than farmer who did not have. The result was consistent with studies by Mbanasor and Kalu [4], Mwita [5], Khan and Ali [12], and Parikh and Shah [22], but against the research of Okike et al. [23] which showed that receiving credit decreased farmers' economic efficiency.

\subsection{Profit efficiency distribution}

The results of the frequency distribution of economic efficiency estimates was presented in the Table 4. The findings revealed that HoaLoc-mango farmers obtained on the average $28.65 \%, 19.65 \%$, and $28.00 \%$ level of profit efficiency in seasons 1,2 , and 3 , respectively. The result depicted economic efficiency gap of approximately $71.35 \%$ in season $1,80.35 \%$ season 2, and $72.00 \%$ in season 3 . This implied that the average farmer in the study area could increase profit by $71.35 \%, 80.35 \%$, and $72.00 \%$ in seasons 1,2 , and 3 , respectively, by improving their economic efficiency.

The result showed that economic efficiency ranged from $0.00-0.89$ in season 1 , and season 3, and from 0.00-0.99 in season 2. The implication of the result indicated that the average HoaLoc-mango farmer required $67.4 \%((1-0.29 / 0.89) * 100)$ in season $1,79.8 \%$ $\left((1-0.20 / 0.99)^{*} 100\right)$ in season 2 , and $68.5 \%((1-0.28 / 0.89) * 100)$ in season 3 cost saving to achieve the status of the most efficient mango grower of production, whereas the least performing of HoaLoc-mango farmers needed 100\% $\left((1-0.00 / 0.89)^{*} 100\right)$ in season 1 , and season 3 , and $100 \%((1-0.00 / 0.99) * 100)$ in season 2 cost saving to become the least efficient mango grower in the Mekong Delta. 
Table 4: Efficiency level distribution of EE sores of HoaLoc-mango.

\begin{tabular}{|c|c|c|c|c|c|c|}
\hline \multirow{2}{*}{$\begin{array}{l}\text { Economic } \\
\text { efficiency level }\end{array}$} & \multicolumn{2}{|c|}{ Season 1} & \multicolumn{2}{|c|}{ Season 2} & \multicolumn{2}{|c|}{ Season 3} \\
\hline & Frequency & Percentage & Frequency & Percentage & Frequency & Percentage \\
\hline$<0.1$ & 41 & 34.75 & 74 & 56.92 & 44 & 32.84 \\
\hline $0.1-<0.2$ & 14 & 11.86 & 14 & 10.77 & 23 & 17.16 \\
\hline $0.2-<0.3$ & 15 & 12.71 & 14 & 10.77 & 15 & 11.19 \\
\hline $0.3-<0.4$ & 6 & 5.08 & 4 & 3.08 & 9 & 6.72 \\
\hline $0.4-<0.5$ & 12 & 10.17 & 5 & 3.85 & 11 & 8.21 \\
\hline $0.5-<0.6$ & 9 & 7.63 & 5 & 3.85 & 10 & 7.46 \\
\hline $0.6-<0.7$ & 9 & 7.63 & 3 & 2.31 & 9 & 6.72 \\
\hline $0.7-<0.8$ & 8 & 6.78 & 3 & 2.31 & 8 & 5.97 \\
\hline $0.8-<0.9$ & 4 & 3.39 & 2 & 1.54 & 5 & 3.73 \\
\hline $0.9-<1.0$ & 0 & 0.00 & 6 & 4.62 & 0 & 0.00 \\
\hline 1.0 & 0 & 0.00 & 0 & 0.00 & 0 & 0.00 \\
\hline $\operatorname{Obs}(\mathrm{N})$ & \multicolumn{2}{|c|}{118} & \multicolumn{2}{|c|}{130} & \multicolumn{2}{|c|}{134} \\
\hline Minimum & \multicolumn{2}{|c|}{0.0001} & \multicolumn{2}{|c|}{0.0001} & \multicolumn{2}{|c|}{0.0001} \\
\hline Maximum & \multicolumn{2}{|c|}{0.8949} & \multicolumn{2}{|c|}{0.9988} & \multicolumn{2}{|c|}{0.8935} \\
\hline Mean & \multirow{2}{*}{\multicolumn{2}{|c|}{$\begin{array}{l}0.2865 \\
0.2691\end{array}$}} & \multicolumn{2}{|c|}{0.1965} & \multicolumn{2}{|c|}{0.2800} \\
\hline Std. deviation & & & \multicolumn{2}{|c|}{0.2627} & \multicolumn{2}{|c|}{0.2674} \\
\hline
\end{tabular}

Source: Field Survey Data, 2018.

\section{CONCLUSIONS}

The result of economic efficiency indicated that season 1 ranked first in terms of economic efficiency, at nearly $28.65 \%$, followed by season 3 , at about $28.00 \%$, and then season 2 , at approximately $19.65 \%$. Adjustments in the input factors could lead to improve profit of HoaLoc-mango growers in the Mekong Delta. More specific, the inputs that were important in determining output in season 1 were the root fertiliser price and land area, in season 2 were the fungicide price, root fertiliser price, leaf fertiliser price and land area, and in season 3 were the labour price and land area

The positive determinants of economic efficiency were the credit access and plant density in season 1, the age, credit access, wrapping bag, and market access in season 2, the credit access in season 3. On the other hand, the constraints to profit of HoaLoc-mango producers were the education, payment for agro-input wholesale on ending of season, and the classifying sale in season 2 .

\section{ACKNOWLEDGEMENTS}

I am Truong Hong Vo Tuan Kiet, a researcher in Can Tho university in Vietnam, a PhD student in Putra Malaysia university, a scholar of SEARCA. I confirm that my article has been carried out from the data source of project in Vietnam with the title "Value chain development of Vietnamese mango fulfilling requirement for domestic and international markets" (2017-2020) and that I have been a key member responsible for content of mango value chain analysis. Thank you to my colleagues for their support (Nguyen Thi Kim Thoa and Pham Thi Nguyen). I would like to publish my article in order to share my result.

\section{REFERENCES}

[1] F.A.O., Major tropical fruits - Statistical compendium 2017, Rome, p. 38, 2019.

[2] General statistic office of Vietnam (GSO), Statistical YearBook 2017, Statistical Publishing House: Hanoi city, Vietnam, 2018. 
[3] Loc, V.T.T., Kiet, T.H.V.T., Son, N.P., An, N.T.T., Tin, N.H., Tho, T.H. \& Huon, L., Analysis of Mango Value Chain in Dong Thap Province, Mekong Delta Development Research Institute, Can Tho University, 2014.

[4] Mbanasor, J.A. \& Kalu, K.C., Economic efficiency of commercial vegetable production system in Akwa Ibom State, Nigeria: A translog stochastic frontier cost function approach. Tropical and Subtropical Agro-Ecosystems, 8, pp. 313- 318, 2008.

[5] Mwita, A.C., Assessment of profit efficiency among sweet yellow passion fruit farmers in Mbeere south, Embu country. Master of Science Thesis (agribusiness management and trade), Kenyatta University, 2016.

[6] Abdur, R.S.M., A study on economic efficiency and sustainability of wheat production in selected areas of Dinajpur district. Master of Science thesis, Bangladesh Agricultural University, 2012.

[7] Bealu, T., Endrias, G. \& Tadesse, A., Factors Affecting Economic Efficiency in Maize Production: The Case of Boricha Woreda in Sidama Zone, Southern Ethiopia. The Fourth Regional Conference of The Southern Nationalities State Economic Development in Hawassa, p. 28, 2013.

[8] Daniel, H.G., Analysis of economic efficiency in potato production: The case of smallholder farmers in Welmera district, Oromia special zone, Oromia, Ethiopia. MA Thesis (development economics), Department of Economics, College of Business and Economics, School of Graduate Studies, Hawassa University, 2016.

[9] Idiong, I.C., Evaluation of technical, allocative and economic efficiencies in rice production system in Cross River State, Nigeria. PhD thesis, Michael Okpara University of Agriculture, Umudike, Nigeria, 2006.

[10] Sibiko, K.W., Mwangi, J.K., Gido, E.O., Ingasia, O.A. \& Mutai, B.K., Allocative efficiency of smallholder common bean producers in Uganda. International Journal of Development and Sustainability, 2(2), pp. 640-652, 2013.

[11] Daniel, O.N., Analysis of production efficiency in Irish potato production in Kenya: The case of Nyandarua North District. Master of Science thesis, Egerton University, p. 79, 2009.

[12] Khan, H. \& Ali, F., Measurement of productive efficiency of tomato growers in Peshawar, Pakistan. Agricultural Economic - Czech, 8, pp. 381-388, 2013.

[13] Khan, H. \& Saeed, H., Measurement of technical, allocative and economic efficiency of tomato farms in Northern Pakistan. International Conference on Management, Economics and Social Sciences (ICMESS'2011), Bangkok, 2011.

[14] Ogunniyi, L.T., Profit efficiency among maize producers in Oyo State, Nigeria. ARPN Journal of Agricultural and Biological Science, 6, pp. 11-17, 2011.

[15] Fried, H.O., Lovell, C.A.K. \& Schmidt, S.S., Productivity and efficiency. The Measurement of Productive Efficiency and Productivity Change, eds, H.O. Fried, C.A.K. Lovell \& S.S. Schmidt, pp. 1-105, Oxford University Press, 2008.

[16] Daraio, C. \& Simar, L., Conditional nonparametric frontier models for convex and nonconvex technologies: a unifying approach. Journal of Productivity Analysis, 28(1), pp. 13-32, 2007.

[17] Lovell, C.A.K., Production frontiers and productive efficiency. The Measurement of Productive Efficiency: Techniques and Applications, eds H.O. Fried \& S.S. Schmidt, Oxford, pp. 3-67, 1993.

[18] Koopmans, T.C., An analysis of production as an efficient combination of activities. Activity Analysis of Production and Allocation, ed. T.C. Koopmans, John Wiley and Sons: New York, 1951. 
[19] Sunday, A.B., Uwemedimo, O.E., Elizabeth, J.N., Kesit, N.K., Daniel, J.E. \& Akwa, I., Economic efficiency of Cassava based farmers in Southern Wetland Region of Cross River State, Nigeria: A translog model approach. International Journal of Humanities and Social Science, 3, pp. 173-181, 2013.

[20] Alam, A., Kobayashi, H., Motsumura, I., Ishida, A. \& Esham, M., Technical efficiency and its determinants in potato production: evidence from northern areas in GilgitBaltistan region. International Journal of Research in Management, Economics and Commerce, 2, pp. 1-17, 2012.

[21] Okoye, B.C. \& Onyenwaku, C.E., Economic efficiency of small-holder cocoyam farmers in Anambra State, Nigeria: A translog stochastic frontier cost function approach. Agricultural Journal, 2, pp. 535-542, 2007.

[22] Parikh, A. \& Shah, M.K., Measurement of technical efficiency in the northwest frontier province of Pakistan. Journal of Agricultural Economics, 45, pp. 132-138, 1994.

[23] Okike, I., Jabbo, M.A., Smith, V., Akinwumi, J.W. \& Ehui, S.K., Agricultural Intensification and Efficiency in West Africa Savannahs: Evidence from Northern Nigeria, Socio-economic and Policy Research Working Paper 33, ILRI: Nairobi, 2001. 